\title{
Elective cesarean section for term breech delivery
}

\author{
Cesariana eletiva na apresentação PÉlvica em gestações a termo \\ Authorship: Febrasgo \\ Participants: Ricardo Simões ${ }^{1,2}$, João de Deus Valadares $\mathrm{Neto}^{1}$, Wanderley M. Bernardo², Antonio J. Salomão ${ }^{1}$, \\ Edmund C. Baracat ${ }^{1}$ \\ Conflict of interest: none
}

${ }^{1}$ Federação Brasileira das Associações de Ginecologia e Obstetrícia (Febrasgo)

${ }^{2}$ Guidelines Project, Associação Médica Brasileira

The Guidelines Project, an initiative of the Brazilian Medical Association, aims to combine information from the medical field in order to standardize procedures to assist the reasoning and decision-making of doctors.

The information provided through this project must be assessed and criticized by the physician responsible for the conduct that will be adopted, depending on the conditions and the clinical status of each patient.

\section{INTRODUCTION}

Breech delivery, with incidence ranging from 3 to $4 \%$ in term gestations, is the second most common delivery presenta$\operatorname{tion}^{1}(\mathbf{D})$. It is a condition in which the baby, at the time of birth, exits the mother's pelvis buttocks- or feet-first. Based on the relation between the baby's lower limbs and the bottom, breech presentation can be classified as: complete (the baby's hips and knees are flexed so that the baby is sitting with feet beside the bottom), and incomplete breech (the baby's legs are folded flat up against the chest); most breech babies are in the incomplete breech position, with bottom coming first. Other types of incomplete breech presentation are the kneeling breech and footling breech ${ }^{1,5}(\mathbf{D})$.

Factors that have been associated with breech presentation include nulliparity, uterine abnormalities, low insertion of placenta, polyhydramnios, oligohydramnios, multiple pregnancy, prematurity, decreased fetal activity, fetal abnormalities and fetal death. Moreover, there is increased risk of recurrence of this type of presentation in subsequent pregnancies.

Many of the factors described above, regardless of the type of presentation and type of delivery chosen, are considered as bad perinatal prognostic markers, associated with increased risk of adverse consequences to the fetus/newborn baby $^{4}(\mathbf{B})$. In addition, breech vaginal delivery is a type of birth with growing difficulties and, in such circumstances, there is increased risk of complications including cord prolapse, difficult delivery and higher maternal and perinatal morbidity. For a long time and even today, the best mode of delivery in this presentation remains, therefore, controver$\operatorname{sial}^{2}(\mathbf{D})^{3}(\mathbf{B})$. Thus, while there is no consensus in the literature regarding the best type of delivery, elective $\mathrm{C}$-section has been often performed in cases of breech presentation.

Considering the great importance of this issue for both mother and baby, as well as the existing controver- sies, a systematic review should be conducted with the purpose of guiding obstetricians, based on the retrieval of the best scientific evidence available, to improve prenatal care and labor in cases of singleton term pregnancies in breech position.

\section{Objective}

The objective of this review is to provide the best evidence currently available on maternal, perinatal and neonatal morbidity and mortality, according to mode of delivery selected for singleton breech pregnancies at term.

\section{Methods}

The evidence used for analysis of maternal, perinatal and neonatal morbidity and mortality, according to mode of delivery chosen in cases of singleton term pregnancies in breech presentation, was obtained according to the following steps: preparation of the clinical question, structuring of the question, search for evidence, critical evaluation, and selection of evidence.

\section{Clinical question}

Is the performance of elective $\mathrm{C}$-section in singleton term pregnancies in breech presentation related to lower maternal, peri- and neonatal morbidity and mortality compared with vaginal delivery?

\section{Structured question}

The clinical question is structured according to the P.I.C.O. components (P [Patient]; I [Intervention]; C [Comparison]; O [Outcome]).

- P: Breech pregnancies at term;

- I: Cesarean-section;

- C: Vaginal deliver; 
- O: Maternal, perinatal and neonatal morbidity and mortality.

\section{Bases of scientific data consulted}

The scientific databases consulted were: PubMed-Medline and Cochrane. Manual search from revisions references (narrative or systematic) was also performed.

\section{Strategies for search of evidence PubMed-Medline}

Strategy: (Cesarean Section OR Cesarean Sections OR Delivery, Abdominal OR Abdominal Deliveries OR Deliveries, Abdominal OR Caesarean Section OR Caesarean Sections OR Abdominal Delivery OR C-Section OR C Section OR CSections OR Postcesarean Section) AND (Breech Presentation OR Fetal Presentation, Breech OR Breech Fetal Presentation OR Presentation, Breech Fetal OR Labor Presentation, Breech OR Breech Labor Presentation OR Presentation, Breech Labor OR Presentation, Breech OR Frank Breech Presentation OR Breech Presentation, Frank OR Presentation, Frank Breech OR Incomplete Breech OR Breech, Incomplete OR Complete Breech OR Breech, Complete).

\section{Cochrane}

Strategy: cesarean section AND breech presentation.

Studies retrieved (4/15/2014) (Table 1)

TABLE 1 Number of studies retrieved with the search strategies used for each scientific database.

\begin{tabular}{ll} 
Database & Number of studies \\
\hline Primary & \\
\hline PubMed-Medline & 1,943 \\
\hline Cochrane & 91
\end{tabular}

\section{Inclusion criteira for studies retrieved}

Selection of studies, assessment of titles and abstracts obtained from the search strategy in the consulted databases was conducted by two researchers with skills in the preparation of systematic reviews, both independent and blinded, strictly observing the inclusion and exclusion criteria previously established. All potentially relevant studies were identified. Whenever the title and the summary were not enlightening, researchers sought the full article.

\section{Study design}

Narrative reviews, case reports, case series and studies presenting preliminary results were excluded from the assessment. Systematic reviews and meta-analyzes were used with the basic purpose of recovering references that perhaps had been lost at first, from the initial search strategy. Studies designed as cohort or controlled clinical trials (randomized or not) were included.

Cohort studies were defined as those with follow-up of patients, the same history, and analysis of prognostic outcomes.

Controlled clinical trials were evaluated according to the Jadad score. ${ }^{6}$

\section{P.I.C.O. Components}

- Patient: nulliparous or multiparous women in labor of a term singleton live fetus (gestational age $\geq 37$ weeks), in breech position (complete or incomplete).

- Intervention: cesarean-section.

- Comparison: vaginal delivery.

- Outcome: the outcomes were divided into maternal and newborn outcomes. Maternal outcomes include early and late endpoints. The early maternal outcomes are: maternal death or severe maternal morbidity (admission to ICU, sepsis and organ failure), bleeding complications (postpartum hemorrhage, anemia, and need for blood transfusion after childbirth) and complications of surgical wound (wound infection, dehiscence or pain). Late maternal outcomes include: complications in breastfeeding, perineal pain, abdominal pain, dyspareunia, urinary incontinence, fecal incontinence, genital dystopia, recurring cesarean delivery in subsequent pregnancy, and uterine rupture in subsequent pregnancy.

Newborn outcomes, in turn, include: perinatal or neonatal death (excluding cases of death related to fatal fetal abnormalities), neonatal morbidity such as seizures (occurring within the first 24 hours of birth or that require two or more drugs to control), Apgar score, birth asphyxia, respiratory complications, infection, need for admission into neonatal intensive care unit, neonatal encephalopathy, trauma at birth (bone fractures, subdural hematoma, cerebral or intraventricular hemorrhage), spinal cord injury, peripheral nerve injury (e.g., brachial plexus injury), disabilities in childhood, hypotonia, intubation or need for ventilation for at least 24 hours, and need for tube feeding for four days or longer.

\section{Language}

Studies available in Portuguese, English, French or Spanish were included.

\section{According to publication}

Only studies with full text available were considered for critical assessment. 
Studies selected in the first assessment

After entering the search strategy in the primary databases (PubMed-Medline and Cochrane), the assessment of titles and abstracts led to the selection of 26 studies.

Evidence selected in critical evaluation and exhibition of results The studies considered for full text reading were critically assessed according to inclusion and exclusion criteria, study design, P.I.C.O., language and availability of the full text.

Results pertaining clinical status will be displayed individually, showing the following items: clinical question, number of studies selected (according to inclusion criteria), description of the studies (Table 2), results and summary of the available evidence. References related to the studies included are shown in Table 3.

\begin{tabular}{l} 
TABLE 2 Worksheet used for description of studies \\
included and exposure of the results. \\
Evidence included \\
\hline Study design \\
\hline Population selected \\
\hline Time of follow-up \\
\hline Outcomes considered \\
\hline Expression of results: percentage, risk, odds, hazard ratio
\end{tabular}

TABLE 3 Selection process.

\begin{tabular}{ll} 
Type of publication & Included \\
\hline Randomized clinical trials & $4^{(8,9,12,14)}$ \\
\hline Concurrent cohort studies & $2^{(18,19)}$ \\
\hline Non-concurrent cohort studies & $20^{(10,11,13,15-17,20-32)}$ \\
\hline
\end{tabular}

After applying the inclusion and exclusion criteria, the evidence selected in the search and defined as randomized controlled trials (RCT) were subjected to an appropriate checklist for critical assessment (Table 3). Critical assessment of RCTs allows to classify them according to the Jadad score, so that Jadad $<3$ trials are considered inconsistent (B), and those with scores $\geq 3$, consistent (A). For critical analysis of non-randomized studies, among them prospective observational studies, we used the Newcastle-Ottawa scale. $^{\text {? }}$

For results with available evidence, wherever possible the following specific items are defined: population, intervention, outcomes, the presence or absence of benefit and/or damage and controversies.

Cost issues will not be included in the results.
The results will be presented preferably in absolute data, absolute risk, number needed to treat (NNT), or number needed to harm (NNH), and occasionally in mean and standard deviation.

TABLE 4 Critical assessment script for randomized controlled trials (checklist).

Study data

Sample size calculation

Reference, study design,

Jadad, strength of evidence

Estimated differences, power, significance level, total number of patients

\begin{tabular}{ll}
$\begin{array}{l}\text { Patient selection } \\
\text { Inclusion and exclusion } \\
\text { criteria }\end{array}$ & $\begin{array}{l}\text { Patients } \\
\text { Recruited, randomized, prognostic } \\
\text { differences }\end{array}$ \\
\hline $\begin{array}{l}\text { Randomization } \\
\text { Description and blinded } \\
\text { allocation }\end{array}$ & $\begin{array}{l}\text { Patient follow-up } \\
\text { Time, losses, migration }\end{array}$ \\
\hline $\begin{array}{l}\text { Treatment protocol } \\
\text { Intervention, control and } \\
\text { blinding }\end{array}$ & Analysis \\
\hline $\begin{array}{l}\text { Outcomes considered } \\
\text { Primary, secondary, }\end{array}$ & intervention and control \\
measuring instrument & Result \\
of the outcome of interest & Benefit or harm in absolute data, \\
\hline
\end{tabular}

\section{RESULTS}

Clinical question

Is the performance of elective $\mathrm{C}$-section in singleton term pregnancies in breech presentation related to lower maternal, peri- and neonatal morbidity and mortality compared with vaginal delivery?

\section{Evidence selected}

The main reasons for the exclusion of works were the unavailability of the full text, longitudinal observational (retrospective or prospective) or experimental (controlled clinical trials, randomized or not) studies with different study design, studies that included preterm fetuses (gestational age $<37$ weeks), or those using only the estimated weight of the fetus as a criterion for inclusion (Table 3 ).

\section{Results of the evidence selected}

Of the 1,943 articles initially retrieved, 26 were selected to support the summary of evidence concerning maternal, perinatal and neonatal morbidity and mortality, according to mode of delivery chosen in cases of singleton term pregnancies in breech presentation. Studies included are shown in Table 3. 
1. Hannah et al. (A). ${ }^{8}$

- Design: multicenter randomized controlled clinical study involving 121 centers distributed in 26 countries, known as term breech trial (TBT).

- Population: 2,088 women in labor of a term singleton fetus (gestational age $\geq 37$ weeks) in complete or incomplete breech position (except those with evidence of cephalopelvic disproportion, estimated fetal weight greater than or equal to $4,000 \mathrm{~g}$, cephalic hyperextension, fatal fetal congenital anomaly, contraindication to vaginal delivery [low lying placenta]), were randomized to elective cesarean delivery $n=1,041$ (performed with gestational age equal to or greater than 38 weeks) or planned vaginal delivery $(\mathrm{n}=1,042)$.

- Outcome: assessing, as the primary outcome, perinatal and neonatal morbidity and mortality up to 28 days after birth, excluding cases related to fatal congenital anomalies. The analysis included birth trauma (bone fractures, subdural hematoma, brain or intraventricular hemorrhage), spinal cord injury, peripheral nerve injury, seizure (within 24 hours of birth or need for two or more drugs to control), Apgar score $<4$ at five minutes, hypotonia, intubation or need for ventilation for at least 24 hours, need for tube feeding for four days or longer, admission into neonatal intensive care unit for longer than four days.

As a secondary outcome, to evaluate maternal morbidity and mortality during the first six weeks postpartum (including maternal death, severe bleeding, need for blood transfusion, need for uterine curettage due to presence of ovular debris, hysterectomy, need for surgical treatment of vulvar or perineal hematoma, pulmonary embolism, pneumonia, infection, fever (not including the first 24 hours postpartum), bowel, bladder or ureter injury requiring surgical treatment, genital tract fistulas).

- Result: of the 1,041 pregnant women randomized to elective cesarean section, 941 (90.4\%) underwent the procedure; among those randomized to planned vaginal delivery $(\mathrm{n}=1,042)$, only 591 underwent the procedure $(56.7 \%)$. The authors found a lower frequency of perinatal and neonatal morbidity and mortality in patients referred to elective cesarean delivery over planned vaginal delivery (factors such as trauma at birth [RRA $=0.017$ with $95 \mathrm{CI}$ : 0.004 to 0.027]; seizure [RRA $=0.011$ with 95CI: 0.002 to 0.013 ]; hypotonia [RRA $=0.028$ with 95CI: 0.016 to 0.033 ]; Apgar $<7$ at 5 minutes [RRA $=0.044$ with
95CI: 0.027 to 0.055 ]; intubation or need for ventilation for at least 24 hours [RRA $=0.019$ with $95 \mathrm{CI}$ : 0.007 to 0.025$]$ ) were significantly reduced among women undergoing cesarean delivery.

Regarding the secondary endpoints analyzed (maternal morbidity and mortality), no significant differences were identified between the groups.

2. Hannah et al. (B). ${ }^{9}$

- Design: multicenter randomized controlled clinical study involving 121 centers distributed in 26 countries, known as term breech trial (TBT).

- Population: 2,088 women pregnant with a term singleton fetus (gestational age $\geq 37$ weeks) in complete or incomplete breech position (except those with evidence of cephalopelvic disproportion [estimated fetal weight greater than or equal to 4,000g], cephalic hyperextension, fatal fetal congenital anomaly, contraindication to vaginal delivery [low lying placenta]), were randomized to elective cesarean delivery $n=1,041$ (performed with gestational age equal to or greater than 38 weeks) or planned vaginal delivery $(\mathrm{n}=1,042)$.

- Outcome: to evaluate, by means of a questionnaire, complaints of urinary and fecal incontinence, and flatus, and to analyze breastfeeding, sexual and emotional relationship with husband/partner, postpartum depression, satisfaction related to the birth experience, and pain (perineal, abdominal) after three months from birth.

- Result: 972 pregnant women randomly assigned to elective cesarean delivery and 962 patients randomized to the planned vaginal delivery were followed for three months providing answers to the questionnaire. Regarding complaints of urinary incontinence, the authors found that these were significantly less frequent among patients submitted to elective cesarean delivery ( $\mathrm{n}=27$ of 725 patients) than among those undergoing planned vaginal birth ( $\mathrm{n}=35$ of 456 patients) with RRA=0.04 (95CI: 0.01 a 0.06$)$. For the other outcomes analyzed, no significant differences between the delivery modes were identified.

3. Golfier et al. (B). ${ }^{10}$

- Design: non-concurrent observational longitudinal study.

- Population: medical records of 1,116 pregnant women (nulliparous and multiparous) with singleton fetus at term (gestational age between 37 and 42 
completed weeks) in complete breech or not, who gave birth in the period between the years 1991 to 1995 were reviewed.

- Outcome: parameters related to maternal morbidity and mortality (cystitis, pyelonephritis, endometritis, abdominal wall abscess, hematoma, surgical trauma, need for blood transfusion, venous thromboembolism, bowel injury and other severe trauma) and neonatal (acidosis, Apgar score $<7$ in the first minute, need for intensive care at birth in the delivery room, brachial plexus injury, scalpel injury, clavicle fracture, pneumothorax, need to transfer to neonatal intensive care units, neurological disorders) were analyzed.

- Result: among the 1,116 patient records analyzed, it was found that 702 patients $(62.9 \%)$ were submitted to elective cesarean delivery and 414 (37.1\%) underwent planned vaginal delivery. The occurrence of Apgar scores $<7$ at $1^{0}$ and $5^{0}$ minutes was higher among women undergoing vaginal delivery $(\mathrm{RR}=1.99$ with $95 \mathrm{CI}: 1.43$ to 2.78 and $\mathrm{RR}=3.05$ with 95CI: 1.03 to 9.05 , respectively). Regarding neurological disorders, these were observed only among patients who underwent vaginal delivery. By analyzing maternal morbidity and mortality, no significant difference was seen with regard to moderate and severe complications between the two delivery modes although mild complications were identified less frequently among patients undergoing vaginal delivery.

4. Daskalakis et al. (B). ${ }^{11}$

- Design: non-concurrent observational longitudinal study.

- Population: records of all births at term, whose fetuses were in breech presentation (singleton pregnancies with a gestational age $>37$ weeks) were analyzed, including the period between 1989 and 2004. Between the years 1988-2000, in the absence of contraindications to vaginal delivery (prior cesarean delivery, fetal weight estimated at more than $3,600 \mathrm{~g}$, biparietal diameter greater than $10 \mathrm{~cm}$, hyperextension of the fetal head, footling presentation), this option was offered to pregnant women. In the years 2001 to 2004, labor was abandoned in cases of breech presentation, pregnancy being resolved with scheduling of cesarean delivery.

- Outcome: parameters related to neonatal morbidity and mortality (subdural hematoma, intracerebral and intraventricular, spinal cord injury, skull base fracture, Apgar score $<7$ at $5^{0}$ minutes, need for intensive care at birth in the delivery room, peripheral nerve injury, need transfer to neonatal intensive care unit stay longer than four days, convulsions within 24 hours from birth or requiring two or more drugs for control, hypotonia for at least two hours, intubation or the need for ventilation at least 24 hours, need for tube feeding for more than four days) were analyzed.

- Result: in the first evaluation period (1988 to 2000), three deaths were identified among babies born vaginally. Significant difference in the occurrence of low Apgar score assessed at $5^{0}$ minutes $(0.64$ versus $0.19 \%)$, birth trauma ( 0.26 versus $0 \%$ ) and admission to neonatal intensive care unit (1.03 versus $0.19 \%$ ) was identified among babies born vaginally compared with cesarean delivery, respectively. Reduction in the risk of hospitalization in the intensive care unit in the second evaluation period (20012004) was also found.

5. Hannah et al. (B). ${ }^{12}$

- Design: multicenter randomized controlled clinical study involving 121 centers distributed in 26 countries, known as term breech trial (TBT).

- Population: 2,088 women pregnant with a term singleton fetus (gestational age $\geq 37$ weeks) in complete or incomplete breech position (except those with evidence of cephalopelvic disproportion [estimated fetal weight greater than or equal to $4,000 \mathrm{~g}$ ], cephalic hyperextension, fatal fetal congenital anomaly, contraindication to vaginal delivery [low lying placenta]), were randomized to elective cesarean delivery $n=1,041$ (performed with gestational age equal to or greater than 38 weeks) or planned vaginal delivery $(\mathrm{n}=1,042)$.

- Outcome: after two years postpartum, women answered a structured questionnaire analyzing duration of breastfeeding, relationship with children and partner/husband, and the existence of health problems in three to six months prior to the submission of the questionnaire.

- Result: of the 1,041 pregnant women randomized to elective cesarean delivery, 497 women provided information for review two years after delivery. Among those randomized to planned vaginal delivery $(\mathrm{n}=1.042)$, in turn, 460 provided information. No difference was seen between the two modes of delivery in the analyzed parameters regarding breastfeeding, relationship with the child and partner/ 
husband, urinary and fecal incontinence, pain (genital and/or abdominal area), dysmenorrhea, menstrual irregularity or hypermenorrhea, depression, sexuality-related issues, or stressful memories related to childbirth.

6. Hopkins et al. (B). ${ }^{13}$

- Design: non-concurrent observational longitudinal study.

- Population: records of all births at term, whose fetuses were in breech presentation (singleton pregnancies with a gestational age $>37$ weeks, up to 42 weeks) were analyzed, including the period between 1989 and 2004.

- Outcome: parameters related to maternal morbidity and mortality (death, blood loss, need for blood transfusion, venous thromboembolism, hematoma, wound infection requiring treatment with antibiotics, endometritis, urinary tract infection and wall dehiscence) were analyzed. Neonatal outcomes examined include: death, convulsions, umbilical artery $\mathrm{pH}$, Apgar score $<4$ at $5^{0}$ minutes, admission to neonatal intensive care unit, brachial plexus injury, cephalohematoma, bone fractures and respiratory distress syndrome of the newborn.

- Result: of 725 patients, 511 underwent cesarean section, while of 214 patients who received assistance in labor, 138 gave birth vaginally. No significant difference was identified between these two modes of delivery with respect to Apgar score, brachial plexus injury, cephalohematoma or fracture. In the analysis of umbilical artery $\mathrm{pH}$ it was possible to identify significant differences favoring cesarean section. There was increased admission to the intensive care unit among newborns born vaginally. With respect to maternal morbidity and mortality, the authors identified significant differences favoring vaginal delivery in terms of blood loss and endometritis. As for parameters such as venous thromboembolism, hematoma or need for blood transfusion, no differences were identified.

7. Whyte et al. (B). ${ }^{14}$

- Design: multicenter randomized controlled clinical study (121 centers distributed in 26 countries) known as term breech trial (TBT).

- Population: 2,088 women pregnant with a term singleton fetus (gestational age $\geq 37$ weeks) in complete or incomplete breech position (except those with evidence of cephalopelvic disproportion [es- timated fetal weight greater than or equal to $4,000 \mathrm{~g}$, cephalic hyperextension, fatal fetal congenital anomaly, contraindication to vaginal delivery [low lying placenta]), were randomized to elective cesarean delivery $n=1,041$ (performed with gestational age equal to or greater than 38 weeks) or planned vaginal delivery $(\mathrm{n}=1,042)$. In selected centers (85), children were analyzed by means of a questionnaire to evaluate their neurodevelopment.

- Outcome: with 23-25 months of age, children were analyzed using a structured questionnaire known as Ages and Stages Questionnaire (ASQ), administered by parents to evaluate five areas relating to child development (communication, fine and gross motor skills, ability to problem solving, and social functioning).

- Result: from the available information of 923 children ( 457 born by elective cesarean delivery and 466 by planned vaginal delivery), there was no significant difference regarding the areas examined by the questionnaire.

8. Krupitz et al. (B). ${ }^{15}$

- Design: non-concurrent observational longitudinal study.

- Population: birth records of all fetuses in breech presentation at term (singleton pregnancies with a gestational age $>37$ weeks $)(n=882)$ were analyzed, including a period of 11 years.

- Outcome: parameters related to neonatal morbidity and mortality (subdural hematoma, intracerebral and intraventricular, spinal cord injury, skull base fracture, Apgar score $<4$ at $5^{0}$ minutes, need for intensive care at birth in the delivery room, peripheral nerve injury, need transfer to neonatal intensive care unit, stay longer than four days, convulsions within 24 hours from birth or requiring two or more drugs for control, hypotonia for at least two hours, intubation or the need for ventilation at least 24 hours, need for tube feeding for more than four days) were analyzed.

- Result: of a total of 882 births, 427 were performed by cesarean section, and 382 vaginally. The neonatal mortality rate was zero in both groups. No significant difference in relation to neonatal morbidity between the two delivery modes was identified.

9. Rietberg et al. (B). ${ }^{16}$

- Design: non-concurrent observational longitudinal study. 
- Population: birth records of all fetuses in breech presentation at term (singleton pregnancies with a gestational age $>37$ weeks) weighing $\leq 4,000 \mathrm{~g}$ $(n=33,024)$ or $>4,000 \mathrm{~g}(\mathrm{n}=2,429)$ were analyzed between 1998 and 2002.

- Outcome: to analyze the mode of delivery (number of planned and emergency cesarean sections, as well as number of vaginal deliveries) and neonatal outcomes (perinatal death, Apgar score at 5 minutes and birth trauma) of fetuses in breech presentation in the 33 months prior to the publication of results of the term breech trial (TBT) and in the 25 months after its publication.

- Result: the authors identified, within two months after publication of the TBT study, an increase in the rate of cesarean sections (50 to $80 \%$ ) for babies born at term in breech position, which was accompanied by a significant reduction in perinatal mortality for newborns with birth weight $\leq 4,000 \mathrm{~g}$.

10. Gilbert et al. (B). ${ }^{3}$

- Design: non-concurrent observational longitudinal study.

- Population: birth records of all fetuses in breech presentation at term (singleton pregnancies with a gestational age > 37 weeks) were analyzed, including the years from 1991 to 1999.

- Outcome: to analyze neonatal morbidity and mortality according to the mode of delivery in cephalic $(n=3,271,092)$ and pelvic $(n=100,730)$ presentations.

- Result: of those born in breech presentation $(\mathrm{n}=100,730), 4,952$ babies were born vaginally, while 60,418 deliveries were performed by cesarean section. Of births occurred vaginally, the authors found that among nulliparous women, this type of delivery was associated with increased neonatal morbidity and mortality compared to those born by cesarean section (neonatal mortality $\mathrm{OR}=9.2$ with $95 \mathrm{CI}$ 3.3 to 25.6 ; asphyxia $\mathrm{OR}=5.7$ with $95 \mathrm{CI} 4.5$ to 7.3 ; brachial plexus injury $\mathrm{OR}=33.9$ with $95 \mathrm{CI} 15.2$ to 76.1 and birth trauma $\mathrm{OR}=5.8$ with $95 \mathrm{CI} 4.7$ to 7.1 ). In women with previous vaginal birth, i.e., multiparous, breech presentation was not associated with significant difference with respect to neonatal mortality between the two types of delivery; however, neonatal morbidity-related outcomes remained increased in vaginal delivery over the cesarean delivery (asphyxia OR=3.9 with 95CI 3.0 to 5.1; brachial plexus injury $\mathrm{OR}=22.4$ with $95 \mathrm{CI} 9.9$ to 50.5 and birth trauma $\mathrm{OR}=4.2$ with $95 \mathrm{CI}$ : 3.4 to 5.3 ).
11. Mailàth-Pokorny et al. (B). ${ }^{17}$

- Design: non-concurrent observational longitudinal study.

- Population: birth records of all fetuses in breech presentation at term $(n=1,345)$ (singleton pregnancies with a gestational age $>37$ weeks) were analyzed, including a period of 12 years.

- Outcome: to analyze neonatal morbidity and mortality (Apgar score at 5 minutes, arterial blood pH $<7.0$, obstetric trauma such as hematoma, skull base fracture, brachial plexus injury, admission to neonatal intensive care unit, seizures within the first 24 hours of life, hypotonia lasting two hours or longer).

- Result: of pregnancies in breech presentation, 808 babies were born vaginally, while 537 were born by cesarean section (233 after a failed vaginal delivery). There was no difference in Apgar score or arterial blood $\mathrm{pH}$. With regard to admission to neonatal intensive care unit and brachial plexus injury, the authors identified a higher frequency among those born vaginally compared to cesarean section.

12. Molkenboer et al. (B). ${ }^{18}$

- Design: concurrent observational longitudinal study.

- Population: assessment by questionnaire (24 months after delivery) of outcomes related to vaginal delivery and cesarean section in women $(\mathrm{n}=183)$ who gave birth to babies in breech presentation.

- Outcome: duration of breastfeeding, relationship with husband/partner and children, sexual relations, pain (headaches, dyspareunia, back, perineal, abdominal), urinary incontinence, leukorrhea, constipation, hemorrhoidal disease, menstrual changes, breast changes, postpartum depression, unpleasant memories regarding the delivery.

- Result: there was no significant difference with regard to maternal morbidity 24 months after the birth of babies born in breech presentation, vaginally or by cesarean section.

13. Goffinet et al. (B). ${ }^{19}$

- Design: concurrent observational longitudinal study conducted in 174 maternity hospitals.

- Population: evaluation of 8,105 women who gave birth to babies at term in breech presentation.

- Outcome: evaluation of perinatal and neonatal mortality (excluding lethal congenital anomalies) within 28 days after delivery, obstetric trauma: clinically significant genital injury, seizures in the first 
24 hours of life or requiring control with two or more drugs, Apgar score at 5 minutes, need for intubation and ventilation for at least 24 hours, need for nasogastric tube for 4 days or longer, admission to the neonatal intensive care unit $\geq 4$ days.

- Result: cesarean section was performed on 5,579 women, while vaginal delivery occurred in 1,796 women. There was no significant difference with respect to neonatal morbidity and mortality after delivery of babies in breech presentation born vaginally or by cesarean section.

14. Al-Inizi et al. (B). ${ }^{20}$

- Design: non-concurrent observational longitudinal study.

- Population: evaluation of 299 pregnant women who gave birth to babies at term in breech presentation between 1996 and 2003.

- Outcome: evaluation of perinatal and neonatal mortality (except fatal congenital anomalies) within 28 days after delivery, obstetric trauma, Apgar score at 10 minutes, need for intubation and ventilation for at least 24 hours, need for nasogastric tube for 4 days or longer, admission to the intensive care unit neonatal $\geq 4$ days.

- Result: there was no significant difference with respect to neonatal morbidity and mortality after delivery of babies in breech presentation born vaginally or by cesarean section.

15. Vendittelli et al. (B). ${ }^{21}$

- Design: non-concurrent observational longitudinal study.

- Population: evaluation of 2,095 women who gave birth to babies at term in breech presentation.

- Outcome: evaluation of perinatal or neonatal morbidity and mortality (transfer to neonatal intensive care unit, need for resuscitation, Apgar score < 7 at 5 minutes, obstetric trauma).

- Result: there was no significant difference with respect to neonatal morbidity and mortality after delivery of babies in breech presentation, born vaginally or by cesarean section.

16. Lowry et al. (B). ${ }^{22}$

- Design: non-concurrent observational longitudinal study.

- Population: evaluation of 941 pregnant women who gave birth to singleton babies at term, in breech presentation ( 756 by cesarean section and 185 vaginally).
- Outcome: developmental dysplasia of the hip.

- Result: increased incidence of dysplasia of the hip among fetuses in breech presentation born vaginally was identified.

17. Pradhan et al. (B) ${ }^{23}$

- Design: non-concurrent observational longitudinal study.

- Population: evaluation of 1,433 pregnant women who gave birth to babies at term, in breech presentation, from 1991 to 2000.

- Outcome: evaluation of perinatal or neonatal morbidity and mortality (Apgar score $<7$ at 5 minutes, need for neonatal intensive care unit, obstetric trauma, seizures, psychomotor development, cerebral palsy, need for special educational support).

- Result: of the 1,433 women who gave birth, 881 babies were born vaginally and 552 by cesarean section. Three deaths occurred among babies born vaginally compared to zero cases in the births performed by cesarean section. There was a higher frequency of need for admission to neonatal intensive care unit, and lower Apgar score at $5 \mathrm{mi}$ nutes among babies born vaginally. No significant difference was found in relation to long-term morbidity (psychomotor development, cerebral palsy, and need for special educational support) among the babies born vaginally or by cesarean section.

18. Rietberg et al. (B). ${ }^{24}$

- Design: non-concurrent observational longitudinal study.

- Population: evaluation of 33,824 pregnant women who gave birth to babies at term, in breech presentation, from 1995 to 1999.

- Outcome: evaluation of perinatal or neonatal morbidity and mortality (Apgar score $<7$ at 5 minutes and obstetric trauma).

- Result: among those born vaginally, a higher frequency of Apgar scores $<7$ at 5 minutes (2.8 versus $0.4 \%$ ) was identified, as well as higher number of obstetric trauma $(0.5$ versus $0.17 \%$ ) and higher neonatal mortality ( 0.39 versus $0.17 \%$ ) compared with those born by cesarean section.

19. Molkenboer et al. (B)..$^{25}$

- Design: non-concurrent observational longitudinal study. 
- Population: evaluation of 238 women who gave birth to babies at term in breech presentation.

- Outcome: evaluation of maternal, perinatal and neonatal morbidity and mortality.

- Result: with regard to maternal, perinatal and neonatal outcomes, there was no difference among women who gave birth vaginally or by cesarean section.

20. Alarab et al. (B). ${ }^{26}$

- Design: non-concurrent observational longitudinal study.

- Population: evaluation of 641 pregnant women who gave birth to babies at term, in breech presentation, from 1997 to 2000 . To choose the type of delivery presentation, estimated fetal weight, gestational age and maternal preference were considered.

- Outcome: of the 641 pregnant women, 343 gave birth by cesarean section. Of the 298 women undergoing trial of labor, 146 gave birth vaginally. The authors sought to evaluate neonatal morbidity and mortality (Apgar score $<7$ at 5 minutes, obstetric trauma and neurological dysfunction).

- Result: with respect to neonatal outcomes, no differences were identified between vaginal delivery and cesarean section.

21. Ulander et al. (B). ${ }^{27}$

- Design: non-concurrent observational longitudinal study.

- Population: comparison, based on medical records, of the results in the short and long term of children born in breech presentation, vaginally $(n=1,270)$ or by cesarean delivery $(n=1,640)$.

- Outcome: evaluation of morbidity and mortality related to the mother (postpartum complications, perineal laceration, thromboembolic events), newborn (Apgar score, obstetric trauma, hypoxia, seizures) and child, after 7-year follow-up (hospitalization, illnesses, development).

- Result: vaginal delivery of fetuses in breech presentation was associated with lower Apgar scores compared to vaginal delivery in cephalic presentation, and compared to cesarean section in breech presentation. Higher risk of obstetric trauma was also observed in vaginal delivery of fetuses in breech presentation compared to cesarean section. For the other outcomes analyzed, no significant differences between the delivery modes were identified.
22. Hellsten et al. (B). ${ }^{28}$

- Design: non-concurrent observational longitudinal study.

- Population: evaluation of 711 women who gave birth to singleton babies at term in breech presentation.

- Outcome: evaluation of neonatal morbidity and mortality (Apgar scores, cord $\mathrm{pH}$, need for admission to neonatal intensive care unit, obstetric trauma and seizures).

- Result: vaginal delivery of fetuses in breech presentation was related to lower Apgar scores at $1 \mathrm{minu}-$ te ( $\mathrm{RR}=9.5$ with 95CI: 2.3 to 40.3 ) and acidemia (arterial $\mathrm{pH}<7$ ) with $\mathrm{RR}=7.6$ (95CI: 1.8 to 32.3 ). For the other outcomes analyzed, no differences were identified.

23. Krebs et al. (B). ${ }^{29}$

- Design: non-concurrent observational longitudinal study.

- Population: evaluation of 15,441 primiparous women who gave birth to singleton babies at term in breech presentation.

- Outcome: evaluation of maternal morbidity and mortality (pelvic infection, puerperal fever, surgical scar dehiscence, thromboembolic events, vesicovaginal fistula, urinary incontinence, fecal incontinence, complications in subsequent pregnancies).

- Result: cesarean elective delivery was associated with lower rates of postpartum fever, pelvic infections, bleeding, anemia and wound dehiscence compared to deliveries by emergency C-section (failure to vaginal delivery). Compared to vaginal delivery, the cesarean section procedure showed increased risk of pelvic infection, and puerperal fever.

24. Giuliani et al. (B). ${ }^{30}$

- Design: non-concurrent observational longitudinal study.

- Population: evaluation of 699 pregnant women who gave birth to babies at term, in breech presentation, from 1993 to 1999.

- Outcome: evaluation of perinatal and neonatal mortality (excluding lethal congenital anomalies) within 28 days after delivery, obstetric trauma, seizures in the first 24 hours of life or requiring control with two or more drugs, Apgar score at $5 \mathrm{mi}-$ nutes, need for intubation and ventilation for at least 24 hours, need for nasogastric tube for 4 days 
or longer, admission to the neonatal intensive care unit, psychomotor development and spasticity.

- Result: regarding the outcomes analyzed, no differences between the delivery modes were identified.

25. Herbst et al. (B). ${ }^{31}$

- Design: non-concurrent observational longitudinal study.

- Population: evaluation of 1,050 pregnant women who gave birth to babies at term, in breech presentation, from 1988 to 2000.

- Outcome: evaluation of perinatal and neonatal morbidity (Apgar score, arterial blood pH, neurological sequelae, admission to neonatal intensive care unit).

- Result: greater frequency of acidemia, Apgar score $<7$ at 5 minutes, and need for admission to intensive care unit were identified among neonates born vaginally.

26. Delotte et al.(B). ${ }^{32}$

- Design: non-concurrent observational longitudinal study.

- Population: evaluation of 568 pregnant women who gave birth to babies at term, in breech presentation, from 1996 to 2005.

- Outcome: evaluation of perinatal and neonatal morbidity (Apgar score and need for admission to neonatal intensive care unit).

- Result: regarding the analyzed outcomes (Apgar score and need for admission to neonatal intensive care unit), there was no difference between the types of delivery.

\section{Discussion}

The term breech trial (TBT) is the largest and most recent randomized controlled multicenter study to evaluate perinatal and neonatal outcomes associated with mode of delivery in fetuses in breech presentation ${ }^{8}(\mathbf{A})$. This study, which included women with a singleton fetus in breech presentation at term pregnancies, compared the perinatal and neonatal outcomes in two groups of patients: one consisting of women undergoing planned cesarean section and another composed of women undergoing planned vaginal delivery. ${ }^{8}$ (A). The authors were able to identify in the first group a lower frequency of combined neonatal and perinatal mortality results, or severe neonatal morbidity, compared to vaginal births, with no significant difference for maternal morbidity and mortality. In the study's follow-up, the groups men- tioned above were reassessed two years after the performance of the elective $\mathrm{C}$-section procedure or planned vaginal delivery and no difference was found between both regarding breastfeeding, relationship with the child and partner/husband, genital or abdominal pain, dysmenorrhea, menstrual irregularity or hypermenorrhea, depression, sexuality-related issues, or stressful memories related to childbirth ${ }^{12}(\mathbf{B})$.

After the publication of the study, almost immediately, there was a rapid change in clinical practice by many obstetricians regarding breech delivery in term pregnancies. This led the American College of Obstetrics and Gynecology (ACOG) and the Royal College of Obstetricians and Gynaecologists (RCOG) to recommend the practice of elective cesarean section in this condition ${ }^{33}(\mathbf{B})^{34}(\mathbf{D})$. However, because of serious methodological flaws identified in later publications that did not allow extrapolation of results obtained by the TBT, both the ACOG and RCOG reassessed their recommendations towards considering the possibility of vaginal birth as an acceptable option in properly selected cases ${ }^{35-37}(\mathbf{D})$.

Observational studies, prospective or not, published after the TBT showed conflicting results with some demonstrating results that favored vaginal delivery ${ }^{15,19-21,25,26,30,32}$ (B). However, we must consider, in the interpretation of such data, especially in retrospective studies, the numerous limitations inherent to design, such as reduced statistical power to detect differences, variation in the protocols of labor assistance, including induction, fetal monitoring and more, which hinders the comparison among trials.

With regard to maternal and neonatal consequences, the results were not consistent in the various studies analyzed. In the evaluation of early maternal outcomes, including maternal mortality, studies published by Hannah et al. and Molkenboer et al. failed to identify significant differences after the occurrence of breech delivery in fetuses born vaginally or by elective C-section ${ }^{8}(\mathbf{A})^{18}(\mathbf{B})$. Regarding maternal morbidity, the findings vary, so that although in the studies by Hannah et al., Golfier et al., Ulander et al. and Molkenboer et al. (2004 and 2007) no significant differences were identified with regard to moderate and severe complications between the two types of delivery, other studies, such as those conducted by Hopkins et al. and Krebs et al., were able to identify variable results, either favoring vaginal delivery or elective cesarean section ${ }^{8}(\mathbf{A})^{9,10-13,18,25,27,29}(\mathbf{B})$.

With regard to the children's outcomes, considering perinatal or neonatal death, some studies failed to identify increased mortality in the group of babies born vag- 
inally $y^{15,19-21}(\mathbf{B})$. However, other studies such as those reported by Gilbert et al. and Pradhan et al. reported a higher incidence of perinatal mortality among vaginal births, and in the study done by Gilbert et al., this risk was increased among nulliparous women ${ }^{3,23}(\mathbf{B})$. In the analysis of neonatal morbidity, including seizures, birth asphyxia, respiratory complications, infection, need for hospitalization in unit neonatal intensive care, neonatal encephalopathy and birth trauma, some studies showed no relationship to the type of delivery and other establishing positive association especially with vaginal births, as the study by Hannah et al., which successfully identified a significantly reduced frequency of seizures, hypotonia, Apgar score $<7$ at 5 minutes and need for intubation or ventilation for at least 24 hours among women undergoing cesarean section (RRA $=0.011$ with 95CI: 0.002 to 0.013 ; RRA $=0.028$ with $95 \mathrm{CI}$ : 0.016 to 0.033 ; RRA $=0.044$ with 95CI: 0.027 to 0.055 and RRA $=0.019$ with 95CI: 0.007 to 0.025 , respectively $)^{8}(\mathbf{A})$.

With regard to long-term consequences for the children, studies do not show significant differences between these modes of delivery ${ }^{14,26,27}(\mathbf{B})$.

\section{EvidenCE SUMmARY}

Based on these results, there is discrepancy with respect to the most appropriate means of delivery in cases of singleton term pregnancies in breech position. Nevertheless, it seems clinically acceptable, after properly discussed with the patient, to admit a recommendation of planned vaginal delivery, considering it as a safe option in selected cases, i.e., provided that the procedure is performed by skillful professionals, experienced in carrying out maneuvers that can facilitate the birth of babies in breech presentation, following specific directions to conduct a breech delivery.

\section{References}

1. Ghosh MK. Breech presentation: evolution of management. J Reprod Med. 2005; 50(2):108-16. Review. PubMed PMID: 15755047.

2. Krebs L. Breech at term. Early and late consequences of mode of delivery. Dan Med Bull. 2005; 52(4):234-52. Review. PubMed PMID: 16764051.

3. Gilbert WM, Hicks SM, Boe NM, Danielsen B. Vaginal versus cesarean delivery for breech presentation in California: a population-based study. Obstet Gynecol. 2003; 102(5 Pt 1):911-7. PubMed PMID: 14672462.

4. Danielian PJ, Wang J, Hall MH. Long-term outcome by method of delivery of fetuses in breech presentation at term: population based follow up. BMJ. 1996; 312(7044):1451-3. PubMed PMID: 8664622

5. Mukhopadhyay S, Arulkumaran S. Breech delivery. Best Pract Res Clin Obstet Gynaecol. 2002; 16(1):31-42. Review. PubMed PMID: 11866495.

6. Jadad AR, Moore RA, Carroll D, Jenkinson C, Reynolds DJ, Gavaghan DJ, et al. Assessing the quality of reports of randomized clinical trials: is blinding necessary? Control Clin Trials 1996; 17:1-12.

7. Wells GA, Shea B, O'Connell D, Peterson J, Welch V, Losos M, et al. The Newcastle-Ottawa Scale (NOS) for assessing the quality of nonrandomised studies in meta-analyses. Disponível em: www.ohri.ca/programs/clinical_ epidemiology/oxford.asp. Acessado: 10 fev. 2014.
8. Hannah ME, Hannah WJ, Hewson SA, Hodnett ED, Saigal S, Willan AR. Planned caesarean section versus planned vaginal birth for breech presentation at term: a randomised multicentre trial. term breech trial Collaborative Group. Lancet. 2000; 356(9239):1375-83. PubMed PMID: 11052579.

9. Hannah ME, Hannah WJ, Hodnett ED, Chalmers B, Kung R, Willan A, et al.; term breech trial 3-Month Follow-up Collaborative Group. Outcomes at 3 months after planned cesarean vs planned vaginal delivery for breech presentation at term: the international randomized term breech trial. JAMA. 2002; 287(14):1822-31. PubMed PMID: 11939868.

10. Golfier F, Vaudoyer F, Ecochard R, Champion F, Audra P, Raudrant D. Planned vaginal delivery versus elective caesarean section in singleton term breech presentation: a study of 1116 cases. Eur J Obstet Gynecol Reprod Biol. 2001; 98(2):186-92. PubMed PMID: 11574129.

11. Daskalakis G, Anastasakis E, Papantoniou N, Mesogitis S, Thomakos N, Antsaklis A. Cesarean vs. vaginal birth for term breech presentation in 2 different study periods. Int J Gynaecol Obstet. 2007; 96(3):162-6. PubMed PMID: 17270188 .

12. Hannah ME, Whyte H, Hannah WJ, Hewson S, Amankwah K, Cheng M, et al.; term breech trial Collaborative Group. Maternal outcomes at 2 years after planned cesarean section versus planned vaginal birth for breech presentation at term: the international randomized term breech trial. Am J Obstet Gynecol. 2004; 191(3):917-27. PubMed PMID: 15467565.

13. Hopkins LM, Esakoff T, Noah MS, Moore DH, Sawaya GF, Laros RK Jr. Outcomes associated with cesarean section versus vaginal breech delivery at a university hospital. J Perinatol. 2007; 27(3):141-6. PubMed PMID: 17036031.

14. Whyte H, Hannah ME, Saigal S, Hannah WJ, Hewson S, Amankwah K, et al.; term breech trial Collaborative Group. Outcomes of children at 2 years after planned cesarean birth versus planned vaginal birth for breech presentation at term: the International Randomized term breech trial. Am J Obstet Gynecol. 2004; 191(3):864-71. PubMed PMID: 15467555.

15. Krupitz H, Arzt W, Ebner T, Sommergruber M, Steininger E, Tews G. Assisted vaginal delivery versus caesarean section in breech presentation. Acta Obstet Gynecol Scand. 2005; 84(6):588-92. PubMed PMID: 15901272.

16. Rietberg CC, Elferink-Stinkens PM, Visser GH. The effect of the term breech trial on medical intervention behaviour and neonatal outcome in The Netherlands: an analysis of 35,453 term breech infants. BJOG. 2005; 112(2):205-9.

17. Mailàth-Pokorny M, Preyer O, Dadak C, Lischka A, Mittlböck M, Wagenbichler P, et al. Breech presentation: a retrospective analysis of 12-years' experience at a single center. Wien Klin Wochenschr. 2009; 121(5-6):209-15. PubMed PMID: 19412751.

18. Molkenboer JF, Debie S, Roumen FJ, Smits LJ, Nijhuis JG. Maternal health outcomes two years after term breech delivery. J Matern Fetal Neonatal Med. 2007; 20(4):319-24. PMID: 17437240.

19. Goffinet F, Carayol M, Foidart JM, Alexander S, Uzan S, Subtil D, Bréart G; PREMODA Study Group. Is planned vaginal delivery for breech presentation at term still an option? Results of an observational prospective survey in France and Belgium. Am J Obstet Gynecol. 2006; 194(4):1002-11. PMID: 16580289.

20. Al-Inizi SA, Khayata G, Ezimokhai M, Al-Safi W. Planned vaginal delivery of term breech remains an option--result of eight years experience at a single centre. J Obstet Gynaecol. 2005; 25(3):263-6. PMID: 16147731.

21. Vendittelli F, Pons JC, Lemery D, Mamelle N; Obstetricians of the AUDIPOG Sentinel Network. The term breech presentation: neonatal results and obstetric practices in France. Eur J Obstet Gynecol Reprod Biol. 2006; 125(2):176-84. PMID: 16099580 .

22. Lowry CA, Donoghue VB, O’Herlihy C, Murphy JF. Elective Caesarean section is associated with a reduction in developmental dysplasia of the hip in term breech infants. J Bone Joint Surg Br. 2005; 87(7):984-5. PMID: 15972916.

23. Pradhan P, Mohajer M, Deshpande S. Outcome of term breech births: 10-year experience at a district general hospital. BJOG. 2005; 112(2):218-22. PMID: 15663587.

24. Rietberg CC, Elferink-Stinkens PM, Brand R, van Loon AJ, Van Hemel OJ, Visser GH. Term breech presentation in The Netherlands from 1995 to 1999: mortality and morbidity in relation to the mode of delivery of 33824 infants. BJOG. 2003; 110(6):604-9. PMID: 12798480.

25. Molkenboer JF, Reijners EP, Nijhuis JG, Roumen FJ. Moderate neonatal morbidity after vaginal term breech delivery. J Matern Fetal Neonatal Med. 2004; 16(6):35761. PubMed PMID: 15621556.

26. Alarab M, Regan C, O'Connell MP, Keane DP, O'Herlihy C, Foley ME. Singleton vaginal breech delivery at term: still a safe option. Obstet Gynecol. 2004; 103(3):407-12. PubMed PMID: 14990399.

27. Ulander VM, Gissler M, Nuutila M, Ylikorkala O. Are health expectations of term breech infants unrealistically high? Acta Obstet Gynecol Scand. 2004; 83(2):180-6. PubMed PMID: 14756737. 
28. Hellsten C, Lindqvist PG, Olofsson P. Vaginal breech delivery: is it still an option? Eur J Obstet Gynecol Reprod Biol. 2003; 111(2):122-8. PubMed PMID: 14597238

29. Krebs L, Langhoff-Roos J. Elective cesarean delivery for term breech. Obstet Gynecol. 2003; 101(4):690-6. PubMed PMID: 12681872

30. Giuliani A, Schöll WM, Basver A, Tamussino KF. Mode of delivery and outcome of 699 term singleton breech deliveries at a single center. Am J Obstet Gynecol. 2002; 187(6):1694-8. PubMed PMID: 12501085.

31. Herbst A, Thorngren-Jerneck K. Mode of delivery in breech presentation at term: increased neonatal morbidity with vaginal delivery. Acta Obstet Gynecol Scand. 2001; 80(8):731-7. PubMed PMID: 11531616.

32. Delotte J, Trastour C, Bafghi A, Boucoiran I, D’Angelo L, Bongain A. [Influence of mode of delivery in term breech presentation on the Apgar score and transfer in neonatal care unit. Results of the management of 568 singleton pregnancies in a level III French maternity]. J Gynecol Obstet Biol Reprod (Paris). 2008; 37(2):149-53. PubMed PMID: 18023999.
33. Hogle KL, Kilburn L, Hewson S, Gafni A, Wall R, Hannah ME. Impact of the international term breech trial on clinical practice and concerns: a survey of centre collaborators. J Obstet Gynaecol Can. 2003; 25(1):14-6. PMID: 12548320 .

34. ACOG committee opinion. Mode of term singleton breech delivery. Number 265, December 2001. American College of Obstetricians and Gynecologists. Int J Gynaecol Obstet. 2002; 77(1):65-6.

35. Keirse MJ. Evidence-based childbirth only for breech babies? Birth. 2002; 29(1):55-9. PMID: 11843791

36. Kotaska A. Inappropriate use of randomised trials to evaluate complex phenomena: case study of vaginal breech delivery. BMJ. 2004; 329(7473):103942. PMID: 15514356.

37. Glezerman M. Five years to the term breech trial: the rise and fall of a randomized controlled trial. Am J Obstet Gynecol. 2006; 194(1):20-5. PMID: 16389006. 